\title{
PULAR O MURO DA ESCOLA PARA MIRAR O MUNDO POR LENTES: O QUE SE ENSINA E O QUE SE APRENDE COM A PERCEPÇÃO AMBIENTAL NA GEOGRAFIA
}

\author{
Edimilson Mota ${ }^{\text {(a) }}$ Thaysa Barbosa de Souza ${ }^{\text {(b) }}$ \\ (a) Universidade Federal Fluminense - GRC, uffmota@gmail.com \\ (b) Universidade Federal Fluminense, thaysabsouza@gmail.com.
}

EIXO: GEOGRAFIA FÍSICA - CURRÍCULO,FORMAÇÃO E PRÁTICAS DE ENSINO.

\begin{abstract}
Resumo
Considerando a Educação Ambiental uma prática política, acredita-se que o aluno pode se revestir e se investir pela cidadania ao se conscientizar da importância social ao conhecer e contribuir para a qualidade de vida do meio ambiente. Pois, contribuir significa se comprometer para exercer direitos e deveres relativos aos cuidados sociais que cerca o cidadão na sua relação com o meio. O presente estudo buscou investigar a percepção ambiental de alunos de escolas da cidade de Campos dos Goytacazes - RJ, moradores do subdistrito de Guarus, para saber o ponto de vista de cada um, sobre as questões relevantes com relação ao seu espaço social-ambiental. Para isso, partiu-se do princípio de que cada um tem diferente forma de observar e de relacionar com o seu espaço-distrito, e com o seu lugar de convivência social. Para fazer o levantamento sobre a percepção ambiental que cada estudante tem com o seu lugar, foram utilizados alguns procedimentos metodológicos para a descrição e a análise dos dados. Um dos instrumentos utilizados foi o registro fotográfico, pois, acredita-se que, a fotografia oferece possibilidades ao observador ao permitir captar elementos imagéticos sobre o meio ambiente que são indispensáveis para a sua leitura.
\end{abstract}

Palavras chave: Geografia Escolar, Educação Ambiental, Percepção Ambiental e Fotografia.

\section{Por que pular o muro?}

Pular o muro da escola é uma tentativa de resposta a uma inquietude pessoal de observador a partir da análise do discurso, primeiramente, sobre a Educação Ambiental, vivenciada nos Estágios Curriculares Supervisionados da Licenciatura em Geografia, realizados em escolas das redes públicas de ensino, na cidade de Campos. Desde então, foi possível notar que o sistema público de ensino demonstra fragilidade na sua base pedagógica no que diz respeito ao acompanhamento das mudanças trazidas pelas novas tecnologias voltadas para as demandas sobre as políticas para o meio ambiente. Contudo, a escola mostra também ser um espaço de possibilidades ao apresentar uma realidade social com diferentes perfis de alunos de diferentes níveis sociais e econômicos, fortemente informatizados e ligados às mídias, a ponto de se manterem conectados em redes sociais até mesmo durante as aulas, como por exemplo, ao fazer o uso do celular. Pois, assim como com este novo estilo comportamental os alunos acabam por interferir na organização espacial com suas compreensões e resistências: 
grafitam muros com o que abraçam como proposta de vida e dão o colorido que podem e que se opõe ao instituído.

A tecnologia, como questão de estudo neste trabalho, não se contém na análise de diferentes aparelhos e instrumentos tecnológicos com respectivos usos. Procura-se também a compreender sua interferência na tessitura da educação escolar, desde as práticas educativas, passando pelo processo de aprendizagem, até à forma como retorna à sociedade na formação de sujeitos . Como afirma Ferreira (2010, p.110) a tecnologia "aproxima real do virtual, visual do sensorial e conhecimento acadêmico do operacional". Assim, tornar alunos em sujeitos ativos em seu próprio processo de ensinoaprendizagem implica prepará-los para o exercício de sua cidadania.

Na busca de desenvolver uma Educação Ambiental crítica, para que sua função seja efetiva inclusive no espaço escolar, torna-se necessário analisar as questões ambientais além do âmbito biológico, alcançando/reconsiderando os fatos sociais e políticos nos quais os indivíduos estão inseridos. Assim, de acordo com Carvalho $(2008$, p.151) é preciso "reposicionar" o ser humano no mundo com intuito de fazê-lo perceber que faz parte daquilo que pretende dominar durante sua existência. A Educação Ambiental, numa abordagem crítica, exige reposicionamentos para contribuir de forma mais consistente com a relação cuidadosa do homem com a natureza.

É nesta perspectiva que a Educação Ambiental torna-se Educação política, como afirma Reigota (2008), demandando que os cidadãos se incumbam de cumprir seus deveres socioambientais concomitamente à luta por direitos igualitários para toda sociedade.

Embasando-se na compreensão de que Geografia e Educação Ambiental são campos de conhecimentos que tratam de signos dinâmicos e que exigem a compreensão de processos complexos, o uso de tecnologias comuns no cotidiano de jovens apresenta-se como alternativa objetiva e potente na transmissão e na aprendizagem de conteúdos.

Fazendo uma breve análise, como um diagnóstico para a pesquisa pretendida, pode ser notado que a efetivação das políticas ambientais no subdistrito de Guarus, no município de Campos dos Goytacazes, ainda está longe de se tornar o ideal no que tange à participação da sociedade civil, a começar pela escola no sentido de se envolver e de se aproximar mais da realidade social já que esta faz parte daquele lugar. E se a escola ainda não consegue vencer isto é preciso potencializar sua ação: vamos pular o muro da escola...

\section{Universo de pesquisa: Que lugar se vê pelas lentes?}


Considerando tais proposições e observando a realidade socioambiental do distrito de Guarus, cidade Campos dos Goytacazes, Rio de Janeiro, pode-se constatar [como será mostrado nesse trabalho] que sua área não recebe a mesma atenção das políticas públicas ambientais como nas áreas centrais da cidade. Feita esta observação, se entende que, é preciso exercer ali a mesma cidadania como que se exerce em outras áreas da cidade e que, a escola, como espaço de reflexão, e de construção de conhecimento, considerando os seus limites, possa vir a contribuir para o despertamento do aluno ao oferecer a ele por meio de práticas pedagógicas e dialógicas conteúdos que discutam os problemas locais.

Trata-se de uma área onde reside uma população pertencente às classes econômicas menos favorecidas do município. São muitas as carências que dificultam a vivência desta população num ambiente saudável.

As desigualdades socioeconômicas entre centro e periferia foram/são (re)modeladas segundo fatores como os impulsos econômicos que a cidade passa/passou com a implantação de planos urbanísticos que não contemplaram de forma eficaz áreas como o distrito em questão.

Delineando o histórico deste distrito, ressalta-se a influência indígena presente na cultura local. Guarus. Seu nome faz menção aos índios que habitavam este território. Antes nomeado como Guarulhos, devido a reivindicações populares foi renomeado como Guarus, para que não houvesse equívocos com a região de Guarulhos, em São Paulo, garantindo a singularidade do subdistrito campista. (Almanaque de Campos, 2014.p.10) ${ }^{1}$.

No histórico do seu desenvolvimento, Guarus vem se configurando um espaço com marcas de segregação sócio espacial, embora, por outro lado, nesse mesmo contexto, vê-se também tipos de empreendimentos, como: o Hospital Geral de Guarus; pequenas indústrias; escolas; bancos; comércio; matadouros, entre outros serviços. Todavia, destacamos também que, com tudo isso, a área ainda sofre com carências na infraestrutura dos Equipamentos Urbanos Comunitários².

Atualmente, temo visto que irregularidades no planejamento urbano da área culminaram em criação de bairros próximos a áreas ambientalmente frágeis, como elucida Soffiati ( 2013, p.29) sobre o processo de favelização existente entorno da Lagoa do Vigário, ele diz que:

\footnotetext{
${ }^{1}$ A tradicional revista "Almanaque de Campos",em sua última edição além de prestar seu serviço de guia da cidade, dedicou-se a fazer uma crônica do histórico campista listando as estórias e enaltecendo os traços culturais da cidade.

${ }^{2}$ Em acordo coma Lei Federal 6.766/79, Equipamentos Urbanos Comunitários são o serviços prestados na área da cultura,lazer,educação, dentre outros. Equipamentos Urbanos são todos os bens de serviços públicos que oferecem rede de esgoto, água tratada,gás canalizado,rede telefônica,energia elétrica,coletas de águas pluviais, praças e similares.
} 


\section{OS DESAFIOS DA GEOGRAFIA FÍSICA NA FRONTEIRA DO CONHECIMENTO \\ Instituto de Geociências - Unicamp Campinas - SP \\ 28 de Junho à 02 de Julho de 2017}

Às suas margens, fixaram-se pessoas ricas e pobres. Estas últimas, expelidas para a periferia do espaço urbano, por condições hostis de existência e pela especulação imobiliária, ergueram uma favela que provoca um impacto ambiental considerável [...] junto a ela aninhou-se também um matadouro cujos dejetos, juntamente com os despejos de esgoto "in natura", devem poluir sobremaneira as suas águas.

Realidade comprovada ao longo do território de Guarus através de observação empírica, associa-se a outras problemáticas ambientais que assolam a área, como a questão da inexistência de jardins, hortos ou áreas verdes que garantam interação entre população e seu ambiente. Tais situações atestam o fato que a segregação sócio espacial, ocasionada pelas deficiências estruturais, culminam na tão sentida e pouco discutida segregação socioambiental.

Através desta sequência de fatos, justifica-se a preocupação sobre a falta que uma sólida Educação Ambiental faz e que, por não fazer, vem produzindo o silenciamento da população atingida por esta realidade.

De certo a "venda nos olhos" e a "mordaça na boca" são frutos da falta de cultura ambiental, dado que, prioritariamente, a preocupação por suplementação alimentar; remédio; acesso a emprego e demais serviços que garantam a sobrevivência estejam incansavelmente na pauta de reivindicações da população às autoridades. Enfatiza-se que isso não absolve lacunas presentes na base educacional como um dos motivos que conduzem a esta situação.

Região detentora do maior contingente de eleitores da cidade, a população de Guarus é composta em maioria por jovens e adultos, na faixa etária de 15 a 64 anos, conforme dados IBGE, censo 2010. Devido ao déficit na qualificação profissional, um quadro de desemprego e sub-empregos se estabelece na região . Como resposta, segundo Cruz (2003), o mercado de trabalho está permeado de clandestinidade, induzindo esta massa de trabalhadores ao subemprego, baixa remuneração e a residir em áreas periféricas, como Guarus.

Este cenário contrapõe-se a vocação Off-shore e portuária da região, afirmando as deficiências quanto ao nível de qualificação da população. Assim, nota-se que o acesso ou não à educação tem sido fator decisório quanto a situação socioeconômica do cidadão.

O quadro educacional público do município apresenta um dos menores índices na qualidade, tendo como base o Índice Desenvolvimento da Educação Básica (IDEB). Mesmo seguindo em lenta progressão, no ano de 2013, as escolas municipais, do ensino fundamental, atingiram índice de 3,4\%, enquanto a média nacional foi estimada em 4,9\%. Os dados do ano de 2015- com índice de 5,0apontam melhora no rendimento escolar contudo uma série deficiências neste setor são encontradas.

Tais dados atestam a vulnerável situação escolar que a população dispõe, talvez esse possa ser uma das possíveis respostas da acomodação do população em relação ao ambiente que vive, impossibilitando de estar ciente quanto seus deveres e principalmente direitos . A negligência 
OS DESAFIOS DA GEOGRAFIA FÍSICA NA FRONTEIRA DO CONHECIMENTO

Instituto de Geociências - Unicamp

Campinas - SP

28 de Junho à 02 de Julho de 2017

educacional encurrala o povo no subemprego, alimentando o ciclo de desigualdade socioeconômica e socioambiental.

Investir no ensino de qualidade é empoderar a população, fazê-la resistente às imposições historicamente estabelecidas pelas elites. Através desta premissa, este trabalho destaca a Geografia escolar como canal que conduz ao processo de sensibilização ambiental.

Como todo bairro residencial, Guarus tem coisas bonitas e feias, boas e ruins. As suas paisagens são como define Santos (2008, p.89) , "um conjunto heterogêneo de formas naturais e artificiais", denominando os raros ambientes que ainda não foram alcançados pelas forças produtivas do homem como "Paisagem Natural" e aos ambientes que possuem rastros da socialização como "Paisagem Artificial". Trata- se de uma área detentora de raras áreas verdes e corpos hídricos ( lagoas, lagos, brejos,etc.) que resiste à interferência humana. Entretanto, na maioria dos espaços, o processo de urbanização e dispersão industrial tornam-se cada vez mais presentes.

Guarus, assim como qualquer outro espaço geográfico, recebe diferenciadas narrativas sobre sua paisagem, de acordo com a percepção do observador. Seguindo as premissas de Santos a paisagem caracteriza "tudo" que a visão é capaz de abarcar, aguçando outros fatores sensoriais como: "cores,movimentos, odores, sons, dentre outros".(SANTOS, 2008, p.89),

A interpretação variada ocorre em razão aos saberes e vivências que cada observador carrega. Assim, a percepção do aluno do ensino médio sobre a questão arbórea do bairro residencial Parque Fundão, do distrito de Guarus, em Campos dos Goytacazes, é diferenciada de um técnico ambiental, que também é distinta da leitura de um antigo morador da mesma área. A realidade apresentada é a mesma, contudo, os recortes são diferenciados. A percepção dimensiona, moldura a paisagem.

Desse modo as (re)leituras da paisagem diagnosticada através das lentes dos alunos/as residentes da área tratada, tendem a situar-nos quanto a percepção do espaço. Assim, ressalta-se a necessidade de pesquisar e difundir através de artigos científicos, noticiários, relatos dos moradores e ações empíricas, as principais questões do distrito em relação a arborização escassa, potencializada pelo descaso com a Educação Ambiental, destacando-se problemas com os quais os moradores convivem sem que haja intervenção das políticas públicas pertinentes e pela educação escolar.

Importante é destacar a obrigatoriedade, prevista na Lei Federal nº 6.766, de dezembro de 1979, chamada lei parcelamento do solo, que impõe aos novos loteamentos disponibilizarem infraestrutura aos moradores, como, por exemplo, cuidados ambientais.

Além disto, mesmo previstos no Plano diretor da cidade (Lei n ${ }^{\circ}$ 7.972, de 31 de março de 2008, Art.56), pode-se atentar ao fato de que não há parques ou áreas verdes no trecho urbano do distrito de Guarus. Foi implantado, no município, no ano 2004, o programa "Mais Verde", voltado à arborização 
da cidade. Contudo, nota-se através de observações e dados noticiados pela prefeitura, que poucos bairros do distrito de Guarus foram atingidos pelo programa.

Procurar pontos com problemas ambientais será uma das fases da pesquisa e será realizada com sujeitos parceiros nela: Que lugar se vê pelas lentes?

\section{Metodologia: Como olhar pelas lentes?}

Considerando tais proposições e observando a realidade socioambiental do distrito de Guarus, pode-se constatar que sua área não recebe a mesma atenção das políticas públicas ambientais como áreas centrais da cidade. Sendo o meu lugar de moradia, penso que é preciso exercer ali a mesma cidadania que busco formar em alunos de Geografia, especialmente com este trabalho. Trata-se de uma área onde reside uma população pertencente às classes econômicas menos favorecidas do município. São muitas as carências que dificultam a vivência desta população num ambiente saudável.

A metodologia de pesquisa com o cotidiano foi utilizada, considerando-se a imprevisibilidade das leituras feitas com base na percepção socioambiental dos alunos em suas rotinas diárias no confronto com o movimento das condições ambientais naturais e sociais. Também se fez a escolha para potencializar a subjetividade de suas escolhas e relações com os saberes geográficos escolares. A adoção da pesquisa com cotidiano permite que o processo de investigação traga à luz fatos presentes no espaço tempo, que ficariam encobertos sob o senso comum, fatos estes que se salientam quando o pesquisador troca as lentes, deixando de "ver" o cotidiano como algo sem valor e passa a "enxergá-lo" como extraordinário, tornando possível analisar como precioso o que antes era habitual. Seguindo esse pressuposto, os "coautores" dessa pesquisa tem as câmeras dos seus celulares legitimadas como material didático, uma vez que alicerçam a prática educativa proposta. Reconhece-se o ato de fotografar como recurso que instigue a reflexão dos fenômenos socioambientais de seus cotidianos, sendo cada fotografia, uma "janela" aberta ao observador que pretende compreender parte de um mundo existente e observado.Conforme Martins (2008, p.45) afirma, o fotógrafo documenta seu imaginário involuntariamente revelando ou omitindo fatos da vida cotidiana, revela sua foto como "representação social e memória do fragmentário".

O ver do aluno fotógrafo, no caso tratado aqui como "Coautores", é exteriorizado. O ato de "fotografar-se" possibilita que fragmento de seus cotidianos e pensamentos façam parte do imaginário de quem se propõe a desvendar esses outros imaginários. A fotografia produzida pelos praticantes da ação da aula - alunos e professores - como recurso didático, adiciona sentido ao conteúdo geográfico, afinal, o conteúdo e imagens disponibilizadas através do material didático adquirem sentido,forma e movimento, quando há possibilidade de contextualizar com cotidiano, o real. Propicia a discussão crítica do mundo através de "escalas imagéticas", da realidade global a realidade local.

Produção e discussão de aprenderes da pesquisa: O que as lentes registraram? 
Embora inseridos no mesmo espaço, os parceiros de pesquisa deixaram transparecer durante a vivência da mesma, os diferentes contextos geográficos que estão inseridos. Destacam suas maneiras de ver o mundo pelo recorte que fazem da visão da paisagem. Quando um espectador se põe a analisar suas produções, observa diferenças que resultam de traços culturais e bagagem de ensino que carregam como particularidades suas. Então, fotógrafo e observador podem realizar tentativas de ler o mundo com suas lentes.

As principais problemáticas ambientais do distrito de Guarus,são reforçadas com a fragilidade socioeconômica que a população está exposta. A falta de intervenção da chamada Educação Ambiental (E.A.) Comunitária, tem encurralado a população em alienação ambiental. A E.A., defende a possibilidade de vivência harmoniosa entre comunidade e seu local de prática cotidiana, através melhoria das condicionantes ambientais (Carvalho,2008).

Esta pesquisa foi desenvolvida com quatro alunos de idades entre 12 e 19 anos, moradores de Guarus, contudo debruço aqui os registros somente do Coautor A.

Este Coautor possui cotidiano similar aos de muitos jovens que se inserem no mercado de trabalho para auxiliar a renda familiar. Resta-lhe pouco tempo para vivenciar seu bairro, mas nota as mudanças que ocorrem em seu espaço.

Observando as ruas, notou que apresentam, gradativamente, singelas melhorias no ambiente urbano, pois passou por planejamento urbano recentemente, com construção das casas populares. Contudo, algumas adversidades ambientais perduram na região, tal como despejo de lixo doméstico nos lotes vazios e despejo de esgoto doméstico na rua (Fotografia 1)

Em contraposição, o Coautor orgulhosamente fotografou a árvore mais importante de sua localidade. Comentou que trata-se do ponto de encontro do bairro, e que churrascos e pequenas comemorações são tradicionalmente realizadas durante o verão, à sua sombra. Salientou que alguns moradores cuidam da mesma e seus arredores. (Fotografia 2)

Coexistem, nessa localidade, estruturas urbanas e conjunturas sociais pertencentes a diferentes tempos históricos, evocando o conceito de rugosidade elaborado por Milton Santos (2000), e que se refere a materializações do passado percebidas na atualidade, as quais representam resquícios de uma divisão de trabalho suas manifestações. Portanto são configurações pretéritas, que permanecem influenciando as ações dos tempos atuais (SABINO e SIMÕES, 2013).

A observação empírica e a análise dos registros fotográficos do Coautor reportam, de imediato, ao conceito de rugosidade. Há na paisagem do Parque Cidade de luz, dialogo entre estruturas urbanas antigas, que possuem traços ruralizados, com criação e venda de animais, cultivo de Hortas e comercialização de insumos agrícolas e outras estruturas atuais. Observa-se que a manutenção das estruturas mais antigas ajudam a manutenção de maior cobertura vegetal na área. 
Segundo o participante da pesquisa, um desses espaços, a chácara do senhor "M.L." localizado a frente de sua residência, comercializa para a vizinhança, ovos e leite. Às vezes, seu dono permite as crianças visitarem os animais. Relatou isto fotografando a entrada da propriedade ( Fotografia 3). Numa esquina próxima, os moradores cultivam uma pequena Horta comunitária para subsistência (Fotografia 4).

Em contraposição, na recente estrutura urbana, planejada pela prefeitura e em outra, invadida pela população carente, prossegue um quadro de violência e pobreza. A violência ocasionada entre embate de facções de drogas tem disseminado impactos na esfera social , possuindo explícita tensão social - ao ponto de ser estabelecido toque de recolhimento - e na esfera ambiental.

Além da alienação ambiental ser um dos fatores que condicionam a vivência num ambiente ecologicamente desequilibrado, o aumento da violência indiretamente ocasiona agravamento deste quadro. O Coautor fotografou uma barricada construída com resíduos sólidos domésticos, como restos de móveis numa rua em frente a sua casa ( Fotografia 4 e fotografia 5). Prática costumeira das populações de Guarus, segundo a parceira, tal montagem na rua é justificada com a finalidade de despertar atenção dos órgãos públicos quanto à localidade, mas o Coautor explanou que, na realidade, trata-se de um bloqueio impedindo ou retardando a entrada de policiais na área. Devido a constante violência os detritos urbanos são recolhidos de 1 a 2 vezes semanalmente,quando anteriormente eram recolhidos minimamente 3 vezes por semana. O acúmulo de detritos orgânicos nas ruas tem aumentado a quantidade de vetores de doenças e de animais peçonhentos.

A situação socioambiental a qual a população está exposta aguarda iniciativas das Políticas Públicas e da ação comunitária. A cada clique, transcendia uma certa repulsa e muitos questionamentos que pudessem responder qual fator que os impulsionou a tal realidade. A desordem não se limita somente ao espaço urbano, atinge o cotidiano, o estado psicológico daqueles que almejam a melhora de seu lugar.

\section{Para não terminar: Por que cada lado do muro da escola é de um jeito?}

Vivenciando no mundo exterior à escola, diferenciados espaços socioambientais, os atores escolares vivenciam no espaço entre muros (não só físicos, mas institucionais) a permanente indagação de como superar conflitos intelectuais, coexistentes entre si, como exercício de suas funções diárias. No meio desse conflito, pairam as paraprendizagens e as dificuldades para que aconteçam. Neste trabalho, concentrei o esforço de tentar "pular" o muro, exercendo uma tentativa de promover aprendizagens que resgatassem o aprendido na escola, mas que se ampliassem em novas construções, libertas de tarefas ou exercícios comuns de sala de aula. Ao longo da pesquisa, usando a fotografia como recurso, percebi a possibilidade da proposta. 
Cabe explicitar, que a abolição do método tradicional e do livro está distante de ser uma alternativa capaz de solucionar tais adversidades. É preciso promover uma junção de saberes: o professor detentor do saber científico e pedagógico, o livro com informações fidedignas e dispostas como desafios e diálogos; o aluno com senso crítico construído através da percepção de sua própria vida. Como preconiza Paulo Freire (2013), a escola deve considerar os saberes dos alunos percebendo tais saberes como socialmente produzidos através do cotidiano, (re)discutindo " a razão de ser de alguns desses saberes em relação ao ensino dos conteúdos".

Para efetivar mudança qualitativa no ensino, torna-se urgente a escola romper com suas amarras que limitam o processo de ensino-aprendizagem . O mundo além da escola, está permeado de conflitos e revoluções políticas,sociais e ambientais que atingem o cotidiano dos alunos. No espaço escolar podese encontrar alicerce e instruções científicas para enfrentamento das dinâmicas socioambientais, em contrapartida, a escola precisa se relacionar e buscar com/no mundo vivido a realidade estudada e uma amplitude de saberes sociais. Torna-se necessário aos professores e alunos ultrapassarem o muro da escola, interconectar as realidades, formar uma conscientização ambiental efetiva e principalmente transformadora a ambos ambientes

\section{Figuras e Tabelas}




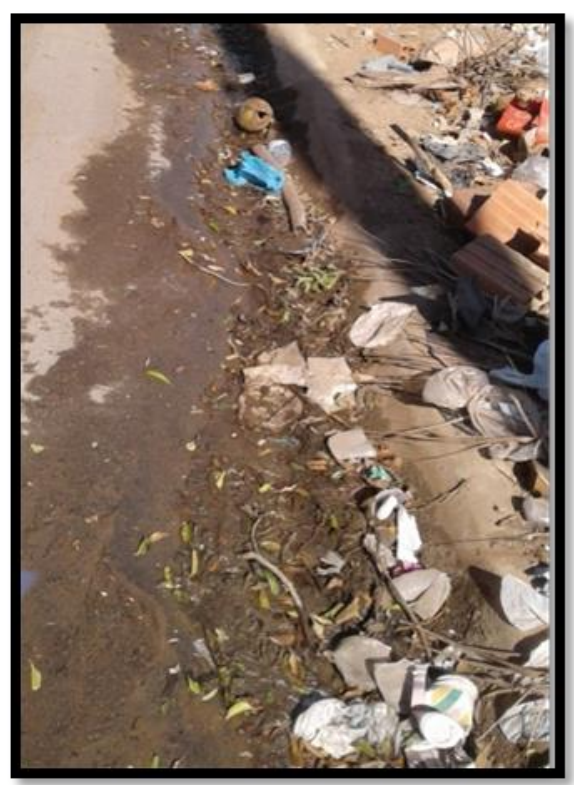

(Fotografia 1 Despejo lixo doméstico na rua)

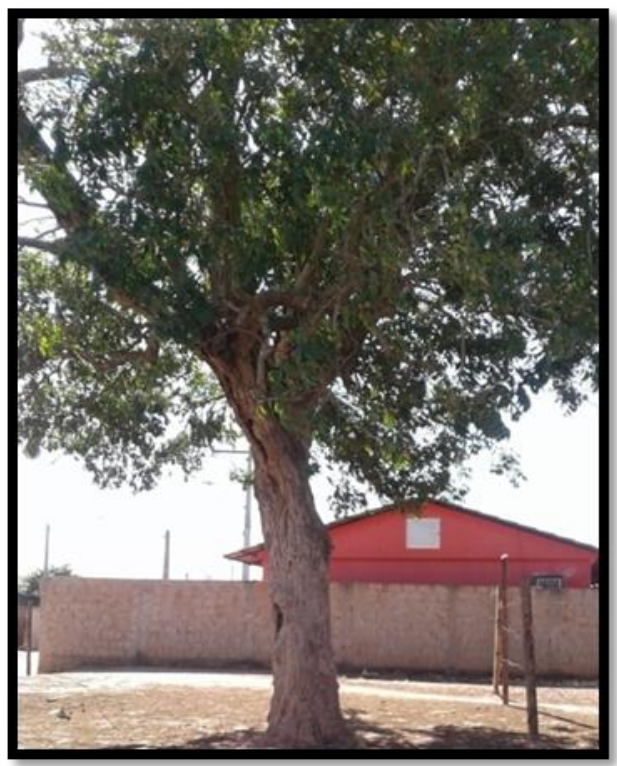

(Fotografia 2 - Árvore "comunitária") 


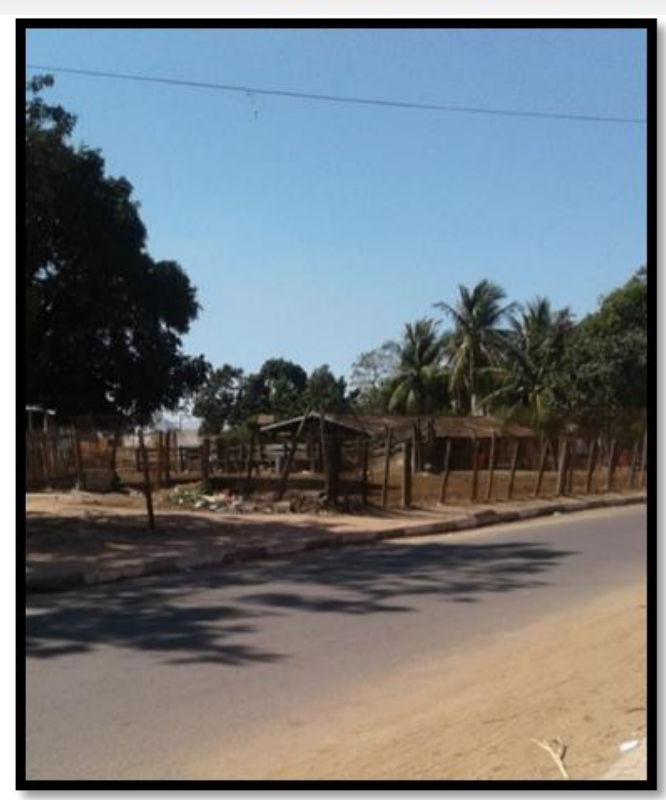

Fotografia 3 - Propriedade rural



(Fotografia 3 - Horta comunitária) 


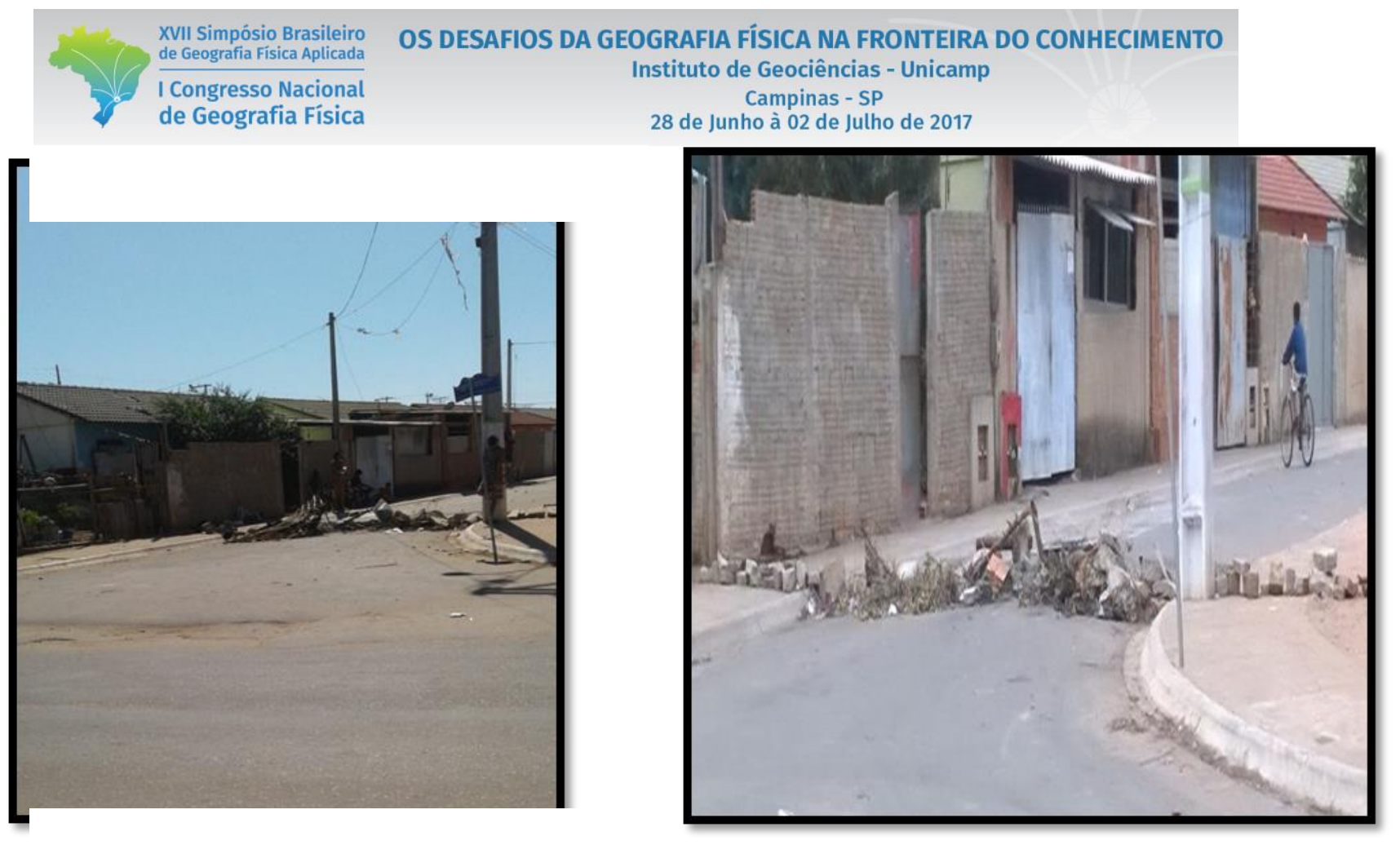

(Fotografia 3 - Barricatas )

\section{REFERÊNCIAS}

ARAÚJO Ronaldo de Souza; AGUIRRE Camila Ayres Ferreira. Espaços Públicos: Áreas verdes em Campos dos Goytacazes e São João da Barra - RJ. Revista Científica Perspectiva Online, Rio de Janeiro,v.5,2013.Disponível em: $<$ http://www.seer.perspectivasonline.com.br/index.php/humanas_sociais_e_aplicadas/article/view/40 > Acessado em: 02 de março de 2016.

BANHARA, Geraldo Donizete. A utilização das novas tecnologias no ensino de geografia, Paraná,17p. Disponível em: http://www.diaadiaeducacao.pr.gov.br/portals/pde/arquivos/2125-8.pdf> acesso em:07/06/2014.

BRASIL. Lei n 9.795, de 27 de Abril de 1999.Educação Ambiental, 1999. Disponível em: http://www.planalto.gov.br/ccivil_03/leis/L9795.htm. Acessado em: 11/06/2016.

CAMPOS DOS GOYTACAZES. Plano Diretor. Lei 7.972, de 31 de março de 2008. Campos dos Goytacazes: Câmara Municipal, 2008

CARNEIRO, Pereira Auner; AZEREDO, Fillipe Gogoy; LEANDRO, Wiara Pessanha. Desenvolvimento Urbano e efetividade dos instrumentos urbanísticos na concepção do direito à cidade: Reflexões jurídicas acerca do Plano Diretor de Campos dos Goytacazes. 1988-2005. (Relatório Final apresentado ao Programa de Fomento à Pesquisa da Fundação Estadual do Norte Fluminense, como Requisito essencial para o cumprimento dos deveres institucionais relacionados aos projeto e comento. - Fundação Estadual do Norte Fluminense ( FENORTE), Rio de Janeiro, 2006. 
XVII Simpósio Brasileiro

de Geografia Fisica Aplicada

I Congresso Nacional

de Geografia Física

Disponível
OS DESAFIOS DA GEOGRAFIA FÍSICA NA FRONTEIRA DO CONHECIMENTO

Instituto de Geociências - Unicamp

Campinas - SP

28 de Junho à 02 de Julho de 2017

http://fdc.br/Arquivos/Mestrado/GruposPesquisa/DesenvMunicipal/RelatorioFenorte.pdf. Acessado em: 15 de maio. 2016

CARVALHO, I. C. de M. Educação Ambiental: a formação do sujeito ecológico. 3. Ed. São Paulo: Cortez, 2008. IBGE (Instituto Geografia e Estatística). Cidades. Disponível em: < http://cidades.ibge.gov.br/xtras/perfil > Acesso em: 13 de maio.2016.

CRUZ, Vianna da José Luis. Projetos Nacionais, Elites locais e Regionalismo: desenvolvimento e dinâmica territorial no Norte Fluminense. Tese (Doutorado em Planejamento Urbano e Reginal)Universidade Federal do Rio de Janeiro. 2003.

Disponível em: <http://www.puro.uff.br > Acesso em: 13 de maio.2016.

FERREIRA, A.A. Produção de materiais didáticos para a diversidade: Patrimônio e práticas de memória numa perspectiva interdisciplinar. Brasília: UFMG, 2000, p.109-135.

FREIRE,Paulo. Pedagogia da Autonomia. 44.ed. São Paulo: Villas Letras,2013.p.15-52.

GÂMBERA,José Leonardo Homem de Melo.Geografia e fotografia: Articulando imagem pela palavra. 2013. Dissertação (Mestrado em Geografia) - Universidade de São Paulo,2013. Disponível em: < http://www.teses.usp.br > Acesso em: 10 de Abril.2016

IDEB RESULTADOS E METAS, INEP (Instituto Nacional de Estudos e Pesquisas Educacionais Anísio Teixeira). Disponível em: < http://ideb.inep.gov.br/resultado> Acesso em: 10 de maio.2016.

LOUREIRO, Carlos Frederico B. Fundamentos da Educação Ambiental: retomando o debate. in: Trajetória e fundamentos da Educação Ambiental. São Paulo:Cortez,2004.p.19-59.

MARTINS,José de Souza. A fotografia e a vida cotidiana: ocultações e revelações. in:_Sociologia da fotografia e da imagem. 2.ed. São Paulo: Editora Contexto, 2011, p.33-62.

MANSANO,Cleres do Nascimento. A Escola e o Bairro: Percepção Ambiental e interpretação do espaço de alunos do Ensino Fundamental. 2006. Dissertação(Programa de Pós graduação em Educação para a Ciência e o Ensino de Matemática)- Universidade Estadual de Maringá, 2006.

Disponível em:

http://www.educadores.diaadia.pr.gov.br/arquivos/File/2010/artigos_teses/GEOGRAFIA/Dissertacoes 12006_cleres_do_nascimento_mansano.pdf > Acesso em: 20 jun.2016.

MONTEIRO, Rafael de Melo; PESSÔA, Vera Lúcia Salazar. Entre poderes, discursos imagens: a análise do discurso e as fotografias como técnicas de investigação das relações de poder no Assentamento Olga Benário em Ipameri/GO. in: MARAFON, Glaucio José; RAMIRES, Julio Cesar de Lima; RIBEIRO, Miguel Angelo; PESSÔA (falta elementos aqui)

REIGOTA, M. O que é educação ambiental. São Paulo: Brasiliense, 2009.

REIGOTA, M. Educação Ambiental: fragmentos de sua história no Brasil. In: Noal, F.O, Reigota, M. e Barcelos, V. H. L. (Orgs). Tendências da Educação Ambiental Brasileira. Santa Cruz do Sul: Edunisc, 1998. p. 11- 25. 
PENTEADO,H. D. Meio Ambiente e Formação de Professores. 4.ed. São Paulo:Cortez,2001. p.53-98.

PEQUENA história de Guarus. Almanarque de Campos, Campos dos Goytacazes-Rio de Janeiro, 2014. Edição especial.

Disponível em: <http://bibliotecavirtual.camaracampos.rj.gov.br> Acesso em: 13 de maio.2016.

SABINO e SIMÕES 2013 Geografia e Arqueologia: Uma visão do Conceito de Rugosidades de

Milton

Santos.

Disponível

em

https://www.academia.edu/4144352/Geografia_e_Arqueologia_uma_vis\%C3\%A3o_do_conceito_de_ Rugosidades_de_Milton_Santos

SANTOS, M. O espaço do cidadão. São Paulo: Nobel, 2000.

SILVA,Osório Peixoto. 500 anos dos Campos dos Goytacazes. ed. Campos dos Goytacazes,Rio de Janeiro:Fundação Cultural Jornalista Oswaldo Lima,2003.

SOFFIATI,Arthu. As lagoas do Norte Fluminense. 1.ed. Campos dos Goytacazes: 2013. p.17-68

TUAN,Yi-Fu. Topofolia- um estudo da percepção, atitudes e valores do meio ambiente. São Paulo:

Difel,1980. 